Trakya Üniversitesi

Eğitim Fakültesi Dergisi

Cilt 8, Say1 2

Ocak 2018 304-317

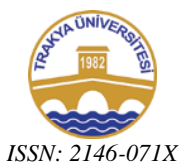

ISSN : 2146-071X
Trakya University

Journal of Education Faculty

Volume 8 , Issue 2

January 2018, 304-317

Doi: $10.24315 /$ trkefd.321973

Geliş Tarihi: 16.06 .2017

Yayına Kabul Tarihi: 01.10.2017

\title{
Sınıf Öğretmeni Adaylarının Matematiksel Düşünmeleri İle Bireysel Yenilikçilikleri Arasındaki İlişkinin Belirlenmesi ${ }^{1}$
}

\section{Identifying the Relationship Between Individual Innovation with Mathematical Thinking of Pre-service Primary School Teachers}

\author{
Alper YORULMAZ², Halil ÇOKÇALIŞKAN ${ }^{3}$, Özkan ÇELİK ${ }^{4}$
}

Öz: Bu araştırmanın amacı, sınıf öğretmeni adaylarının matematiksel düşünme ile bireysel yenilikçilik durumları arasındaki ilişkiyi belirlemektir. Amaç doğrultusunda araştırma ilişkisel tarama modelinde gerçekleştirilmiştir. Veri toplama aracı olarak matematiksel düşünme ölçeği ile bireysel yenilikçilik ölçeği kullanılmıştır. Araştırmanın örneklemini 2015-2016 eğitim öğretim yılı bahar döneminde Muğla Sttkı Koçman Üniversitesi Eğitim Fakültesi Sınıf Öğretmenliği Lisans Programında öğrenim görmekte olan öğretmen adayları arasından seçkisiz yöntemle belirlenen 223 sınıf öğretmeni adayı oluşturmaktadır. Araştırma sonuçlarına göre, sınıf öğretmeni adaylarının matematiksel düşünme durumlarının yüksek, bireysel yenilikçiliklerine ilişkin durumlarının orta düzeyde, bireysel yenilikçilik kategorilerinden en fazla sorgulayıcı olduğu ortaya çıkmıştır. Matematiksel düşünme ile bireysel yenilikçilik durumları arasındaki ilişki incelendiğinde orta düzeyde pozitif yönde anlamlı bir ilişkinin olduğu ortaya çıkmıştır. Sınıf öğretmenlerinin yetiştirilmesi aşamasında matematiksel düşünmeyi geliştirici etkinliklerin tasarlanması, planlanması ve uygulanmasına yönelik etkinlikler gerçekleştirilerek bireysel yenilikçilikleri desteklenebilir.

Anahtar sözcükler: Öğretmen, eğitim, yenilikçi, matematik, üst düzey düşünme, sorgulaylcl.

\begin{abstract}
The aim of the study is determine the relationship between mathematical thinking and individual innovations of pre-service primary school teachers. The correlational research method was used. Mathematical Thinking Scale and Individual Innovation Scale were used as data collection instrument. The sapling was constituted from 223 pre-service primary school teachers who studied in Muğla Sttkı Koçman University, Faculty of Education and Department of Primary School Teacher Education in 2015-2016 academic year. According to the result of this study, it was found that the mathematical thinking level of the participants was high, the level of individual innovation was moderate. From the categories of the individual innovation, critical had the highest score in this study. As for the relationship between mathematical thinking and individual innovation, a moderate positive relationship was
\end{abstract}

\footnotetext{
131 Mayıs- 3 Haziran 2016 tarihlerinde Muğla'da gerçekleştirilen 3. Uluslararası Avrasya Eğitim Araştırmalar Kongresinde sözlü bildiri olarak sunulmuştur.

${ }^{2}$ Arş.Gör., Muğla Sttkı Koçman Üniversitesi, e-posta: alperyorulmaz07@gmail.com

${ }^{3}$ Arş.Gör., Muğla Sitkı Koçman Üniversitesi, e-posta: hcokcaliskan@mu.edu.tr

${ }^{4}$ Aş.Gör.Dr., Muğla Sitkı Koçman Üniversitesi, e-posta: ocelik@ @u.edu.tr
} 
observed. Individual innovations can be promoted through activities aimed at designing, planning and implementing mathematical thinking improvement activities in the course of the upbringing of classroom teachers.

Keywords: Teacher, education, innovative, math, higherorderthinking, critical thinking

\section{GIRİŞ}

Bilim ve teknolojide meydana gelen değişimler bilginin hızlı bir şekilde dönüşümünü sağlamaktadır. Bu dönüşümü takip etmek, uyum sağlamak için bireyin çağın ihtiyacına uygun bilgi ve becerileri kazanması gerekmektedir. Bireye istenen bilgi ve becerilerin kazandırılmasında eğitim programları önemli bir yere sahiptir. Türkiye'de 2015 yılında uygulamaya konulan İlkokul Matematik Dersi Öğretim Programında (MEB, 2015) benimsenen yaklaşım doğrultusunda matematiksel düşünme, problem çözme, akıl yürütme, matematiksel modelleme, matematik dilini kullanarak iletişim, araç ve gereçleri uygun şekilde kullanma, bilgi ve iletişim teknolojilerini kullanma programın temel unsurları olarak belirlenmiştir.

Programın temel unsurları olan matematiksel düşünme öğrencilere kazandırılması gereken temel becerilerden biridir. Matematik eğitiminde önde gelen kuruluşlardan olan Ulusal Matematik Öğretmenleri Konseyi (National Council of Teachers of Mathematics) NCTM matematiksel düşünmenin önemini vurgulamıştır. NCTM (2000) tarafindan yayınlanan Prensipler ve Standartlarda günlük hayatta ve iş yaşamında matematiği anlama ve kullanabilme ihtiyacının giderek arttığı ve mesleki alanlarda matematiksel düşünme ve problem çözmeye daha fazla ihtiyaç duyulduğu belirtilmiştir.

Matematiksel düşünmeyi; Mason, Barton ve Stacey (2010) karmaşı fikirleri arttıran, anlayışı genişleten dinamik bir süreç, Henderson (2002) problemlerin çözümünde açık olarak veya olmayarak matematiksel süreçlerin uygulanması, Yıldırım (2000) bir sorun ya da problemi çözme etkinliği olarak tanımlamıştır. Breen ve O’Shea (2010) ise matematiksel düşünmenin varsayımda bulunma, akıl yürütme, kanıtlama, soyutlama, genelleme ve özel durumlar üzerinde çalışma şeklinde süreçleri içeren bir bütün olduğunu ifade etmiştir. $O$ halde matematiksel düşünme üst düzey düşünme becerilerini içeren (Polya, 1945), sadece sayıların ve soyut matematiksel kavramların yer aldığı durumlarda değil günlük yaşamın içinde de gerçekleştirilebilecek bir düşünme biçimidir (Yeşildere \& Türnüklü, 2007). Bundan dolayı matematik öğretiminde ve tüm disiplinlerde öğrencilere matematiksel düşünme becerisinin kazandırılması önemlidir (Tataroğlu Taşdan, Çelik \& Erduran, 2013). Öğrencilerde matematiksel düşünmenin gelişimi eğitim sistemleri içerisinde programların gelişimine dayanak noktasıdır (Mubark, 2005). Çünkü matematiksel düşünme öğretmenin bilgisinin yenilenmesi ile gelişim sağlayan ve ilerleyen bir süreçtir (Wilson, Mojico \& Confrey, 2013). Matematiksel düşünmenin gelişimi için öğretmenin kendini güncelleyip yeniliklere açık olması gerekir.

Öğretmenlerin bilgisinin yenilenerek matematiksel düşünme becerilerinin geliştirilmesi ile sorunu açıklama ve çözüm bulma, bunun doğruluğunun ispatlanması, yetiştirilecek bireyin hızlı değişimlerin yaşandığı dünyamızda, bugünü ve geleceği keşfetmede ihtiyaç duyacakları beceri ve tutumlarını geliştirecek, karşılaştıkları günlük yaşam problemlerini çözmede matematiksel akıl yürütme yollarını kullanarak yeni fikirler ortaya koymalarını sağlayacaktır. Yeni fikirlerin ortaya konulması 
değişime karşı istekliliği ortaya koyacak ve bu durum yenilikçilik kavramını ortaya çıkaracaktır.

Yenilikçilik; değişime karşı isteklilik, değişime veya yeni şeyleri denemeye isteklilik (Braak, 2001), benimseme sürecinde bir sosyal sistem içerisindeki bireylerin veya kurumların herhangi bir yeniliği diğerlerine göre daha önce benimseme derecesi (Rogers, 2003), girişimci bireylerin sahip oldukları en önemli özelliklerden biri (Herron, 1992) olarak tanımlanmaktadır. Bunun yanında yenilikçilik risk alma, deneyime açıklık, yaratıcılık, fikir liderliği gibi kavramların özelliklerini de içerisinde barındıran bir kavram olarak değerlendirilmektedir (Kılıçer ve Odabaşı, 2010). Toplum içerisinde bireyler sahip oldukları kişisel özellikler nedeniyle yenilikçiler, öncüler, sorgulayıcılar, kuşkucular ve gelenekçiler olarak gruplandırılmaktadırlar (Rogers, 2003). Yenilikçilik, toplumda bireysel olarak farklılık gösteren bir durum olduğundan bireysel yenilikçilik kavramı ortaya çıkmıştır. Bireysel yenilikçilik ise yeniliği geliştirmek, benimsemek ve hayatında uygulamak olarak tanımlanmaktadır (Yuan \& Woodman, 2010). Öğretmenin gelişim ve değişime duyarsız kalmayarak yenilikleri hayatında uygulaması gerekmektedir. Öğretmen niteliklerinden biride yenilik ve gelişmelere açık olmak ve kendini sürekli olarak yenileyebilmektir (Çelikten, Şanal \& Yeni, 2005; Şişman, 2007). Bu görüşten hareketle öğretmen gelişimi ile yenilikçiliğin birbiriyle bağlantılı olduğu vurgulanmıştır (Fullan \& Pomfret, 1977). Öğretmenlerin eğitim ve öğretim ile ilgili araştırmalar yürütmesi, yenilikçi eğitim teorilerini öğrenmesi ve derslerinde uygulanması, yenilikçi düşünce ve uygulama becerileri için yararlıdır (Xu \& Chen, 2010). Öğretmenlerin bireysel yenilikçiliklerinin geliştirilmesi öğrencinin fikirlerinin genişlemesini, sorun ya da problemleri çözme becerisinin gelişmesini sağlayacaktır.

$\mathrm{Bu}$ bağlamda matematiksel düşünme becerileri ile bireysel yenilikçilikleri arasındaki ilişkinin belirlenmesi sınıf öğretmeni adaylarının öğretim sürecinde matematiksel düşünmeyi geliştirici etkinlikleri seçmesi bakımından önemlidir. Bunun yanında bireysel yenilikçiliğe sahip bireylerin yetiştirilmesi toplumların gelişimini arttıracak, yeni fikirlerin ortaya çıkmasını sağlayacağından bireysel yenilikçilik ile matematiksel düşünme arasında bir ilişkinin olup olmadığının belirlenmesi önem göstermektedir.

\subsection{Araştırmanın Amacı}

$\mathrm{Bu}$ araştırmanın amacı, sınıf öğretmeni adaylarının matematiksel düşünme becerileri ile bireysel yenilikçilik durumları arasındaki ilişkiyi belirlemektir. Bu amaç doğrultusunda araştırmanın alt amaçları şunlardır:

1. Sınıf öğretmeni adaylarının matematiksel düşünme düzeyleri nasıldır?

2. Sınıf öğretmeni adaylarının bireysel yenilikçilik durumları nasıldır?

3. Sınıf öğretmeni adaylarının matematiksel düşünme becerileri ile bireysel yenilikçilik durumları arasında bir ilişki var mıdır?

\section{YÖNTEM}

\subsection{Araştırma Deseni}

Sınıf öğretmeni adaylarının matematiksel düşünme durumları ile bireysel yenilikçilikleri arasındaki ilişkinin belirlenmesi amaçlandığından araştırmada ilişkisel (korelasyonel) tarama modeli kullanılmıştır. İlişkisel araştırmalar, iki ya da daha fazla değişken arasında ilişki bulunup bulunmadığını belirleyen araştırma desenleridir (Karasar, 2014). 


\subsection{Evren Örneklem}

Araştırmanın evrenini, 2015-2016 eğitim öğretim yılı bahar döneminde Muğla Sıtkı Koçman Üniversitesi Eğitim Fakültesi Sınıf Öğretmenliği Lisans Programında öğrenim gören 385 öğretmen adayı oluşturmaktadır. Araştırmanın örneklemini ise basit tesadüfi örneklem yoluyla belirlenen, 223 sınıf öğretmeni adayı oluşturmuştur. Örnekleme ilişkin betimsel istatistikler Tablo 1 'de verilmiştir.

Tablo 1. Örnekleme ilişkin betimsel istatistikler

\begin{tabular}{llcc}
\hline \multicolumn{2}{c}{ Değişkenler } & Frekans (f) & Yüzde (\%) \\
\hline \multirow{2}{*}{ Cinsiyet } & Kadın & 171 & 76.7 \\
& Erkek & 52 & 23.3 \\
\hline \multirow{3}{*}{ Sınıf düzeyi } & 1. Sınıf & 76 & 34.1 \\
& 2. Sınıf & 69 & 30.9 \\
& 3. Sınıf & 53 & 23.8 \\
& 4. Sınıf & 25 & 11.2 \\
\hline \multirow{3}{*}{ Akademik not ortalaması } & 2.00 ve altı & 11 & 4.9 \\
& $2.01-2.50$ & 63 & 28.3 \\
& $2.51-3.00$ & 74 & 33.2 \\
& $3.01-3.50$ & 61 & 27.4 \\
& 3.51 ve üzeri & 14 & 6.3 \\
\hline
\end{tabular}

\subsection{Veri Toplama Aracı}

Araştırmada öğretmen adaylarının demografik özelliklerini belirlemede "Kişisel Bilgi Formundan", matematiksel düşünmelerini belirlemede "Matematiksel Düşünme Ölçeğinden" ve bireysel yenilikçilik durumlarının belirlenmesinde "Bireysel Yenilikçilik Ölçeğinden” yararlanılmıştır. Ölçeklere ilişkin ayrıntılı bilgi aşağıda sunulmuştur.

Kişisel bilgi formu: $\mathrm{Bu}$ formda, araştırmaya katılan sınıf öğretmeni adaylarının; cinsiyet, sınıf düzeyi ve akademik not ortalaması değişkenlerine ilişkin bilgiler yer almaktadir.

Matematiksel düşünme ölçeği (MDÖ): Matematiksel düşünme durumlarını belirlemek için Ersoy ve Başer (2013) tarafından geliştirilmiştir. Ölçek 5'li likert tipi olup dört [üst düzey düşünme eğilimi (6), akıl yürütme (4), matematiksel düşünme becerisi (8) ve problem çözme (7)] faktör ve 25 maddeden oluşmaktadır. Araştırma kapsamında ölçeğin, yapı geçerliğinin tespit etmek için doğrulayıcı faktör analizi yapılmıştır. Matematiksel Düşünme Ölçeği'nin geçerli bir yapısının olması nedeniyle, araştırmada Açımlayıcı Faktör Analizi (AFA) yerine, yapıyı doğrulamak amacıyla Doğrulayıcı Faktör Analizi (DFA) yapılmıştır. Tablo 2'de verilen DFA sonuçlarının önerilen değerler aralığında çıktığı görülmüştür. Yapılan bu analiz sonucunda ölçekte yer alan maddelerin orjinalinde yer alan faktörler altında toplandıkları ortaya çıkmıştır. Matematiksel düşünme ölçeğinin alt boyutlarının Cronbach Alpha güvenirlik katsayılarının .83 ile .91 arasında değişmekte olduğu, ölçeğin genel güvenirlik değerinin ise .87 olduğu ortaya çıkmıştır. Bu sonuçlar doğrultusunda ölçek ile yapılan ölçümün güvenilir olduğu sonucuna ulaşılmaktadır. 
Bireysel yenilikçilik ölçeği (BYÖ): Bireysel yenilikçilik ölçeği Hurt, Joseph ve Cook (1977) tarafından geliştirilmiş olup Türkiye'ye uyarlanması Kılıçer ve Odabaşı (2010) tarafından yapılmıştır. Ölçek 5'li likert tipinde olup, 20 maddeden oluşmaktadır. Ölçek; bireylerin değişime ve yeniliğe karşı kaygılarını ortaya koyan "Değişime direnç"(8), bireyleri ait oldukları grup içerisindeki diğer bireylerden önde k1lan özellikleri yansıtan "Fikir önderliği"(5), bireylerin yeniliği aramaya ve denemeye karşı isteklerini ortaya koyan "Deneyime açıklık"(5) ve bireylerin belirsizlikler karşısında yılmayıp güdülenmelerini yansıtan "Risk alma"(2) olmak üzere dört faktörden oluşmaktadır. Araştırma kapsamında ölçeğin, yapı geçerliğinin tespit etmek için DFA yapılmıştır. Tablo 2'de verilen DFA sonucunun önerilen değerler arasında çıkmasından dolayı dört faktöre ilişkin yer alan maddelerin, ölçeğin orijinalinde ki faktörlerin altında toplandığı belirlenmiştir. Bireysel yenilikçilik ölçeğinin alt boyutlarının Cronbach Alpha güvenirlik katsayıları .71 ile .82 arasında değişmekte olduğu, ölçeğin genel güvenirlik değerinin ise .75 olduğu ortaya çıkmıştır. $\mathrm{Bu}$ sonuçlar doğrultusunda ölçek ile yapılan ölçümün güvenilir olduğu sonucuna ulaşılmaktadır.

Matematiksel düşünme ölçeği ve bireysel yenilikçilik ölçeğine ilişkin yapılan Doğrulayıcı Faktör Analizi (DFA) sonuçları Tablo 2'de verilmiştir. Yapılan DFA sonucunda ölçeklerin kullanılabileceği sonucuna ulaşılmıştır.

Tablo 2. Matematiksel düşünme ölçeği ve bireysel yenilikçilik ölçeklerinin doğrulayıcı faktör analizi sonucunda elde edilen uygunluk değerleri

\begin{tabular}{ccccc}
\hline Analiz Türü & & Önerilen Değerler & MDÖ & BYÖ \\
\hline & X2/df & $3-5$ & 3,24 & 3,36 \\
& p-değeri & $<0,05$ & 0,000 & 0,000 \\
Doğrulayıcı Faktör Analizi & RMSEA & $\leq 0,08$ & 0,08 & 0,07 \\
& SRMR & $\leq 0,08$ & 0,04 & 0,06 \\
& GFI & $0,80-0,89$ & 0,83 & 0,87 \\
& AGFI & $0,80-0,89$ & 0,82 & 0,81 \\
\hline
\end{tabular}

\subsection{Veri Analizi}

Araştırmada ölçme araçları 248 kişiye uygulanmıştır. Uygulanan formlar değerlendirilerek 25 tanesinin hatalı veya eksik doldurulduğu tespit edilmiştir. İnceleme sonrasında 223 öğretmen adayına ait veriler puanlandırılarak SPSS 21.0 programına girilmiştir. Kullanılan ölçeklerin yapı geçerliğinin belirlemek için Doğrulayıcı Faktör Analizi, güvenirliğinin belirlenmesinde ise Cronbach Alpha analizleri yapılmıştır. Sınıf öğretmenlerinin demografik özelliklerini belirleyici frekans (n) ve yüzde (\%) değerleri çıkarılarak ölçeklerin tüm alt boyutlarının puanları için ortalama $(\overline{\mathrm{X}})$ ve standart sapma $(\mathrm{Ss})$ hesaplanmıştır. Matematiksel düşünme ile bireysel yenilikçilik arasındaki ilişkinin saptanması için Pearson Çarpım Momentler Korelâsyon Analizi kullanılmıştır. Bireysel yenilikçilik ölçeğinden alınan puanlara göre kategorilere ayrılmıştır. Bu kategorilerin oluşmasında Kılıçer ve Odabaşı (2010) tarafından yapılan puanlama ölçütü dikkate alınmıştır. $\mathrm{Bu}$ ölçüte göre bireylerin ölçekten aldıkları toplam puan 80 puan üstünde ise "Yenilikçi", 69 ve 80 puan arasında ise "Öncü", 57 ve 68 puan arasında ise "Sorgulayıcı", 46 ve 56 puan arasında 
ise "Kuşkucu", 46 puan altında ise "Gelenekçi" olarak yorumlanmıştır. Ayrıca Matematiksel Düşünme Ölçeğinden alınan puanlarda üç ayrı kategoriye ayrılarak ortalaması 1-2.33 arası olanlar "düşük", 2.34-3.67 arası olanlar "orta", 3.68-5 arası olanlar ise "yüksek" düzey olarak yorumlanmıştır.

\section{BULGULAR}

$\mathrm{Bu}$ bölümde ölçme araçlarından elde edilen veriler analiz edilmiş ve elde edilen bulgular yorumlanarak sunulmuştur.

\subsection{Araştırmanın Birinci Alt Problemine İlişkin Bulgu ve Yorum}

Araştırmanın birinci alt problemi olan "Sınıf öğretmeni adaylarının matematiksel düşünme düzeyleri nasıldır?" sorusunu yanıtlamak amacıyla yapılan analizlere ilişkin bulgular Tablo 3'de sunulmuştur.

Tablo 3. Sınıf öğretmeni adaylarının matematiksel düşünmeye ilişkin durumları

\begin{tabular}{lcccccc}
\hline Değişken & $\mathbf{n}$ & $\mathbf{k}$ & $\mathbf{S s}$ & $\overline{\mathbf{X}}$ & $\overline{\mathbf{X}} / \mathbf{k}$ & Düzey \\
\hline Üst düzey düşünme & 223 & 6 & 4.24 & 23.88 & 3.98 & Yüksek \\
Akll yürütme & 223 & 4 & 3.23 & 16.35 & 4.08 & Yüksek \\
Matematiksel düşünme becerisi & 223 & 8 & 3.51 & 28.38 & 3.54 & Orta \\
Problem çözme & 223 & 7 & 3.48 & 24.88 & 3.55 & Orta \\
\hline Matematiksel düşünme durumu & 223 & 25 & 12.42 & 93.50 & 3.74 & Yüksek \\
\hline
\end{tabular}

Tablo 3'e göre sınıf öğretmeni adaylarının matematiksel düşünme durumu ( $\overline{\mathrm{X}}$ $=3.74)$ yüksek düzeyde; alt boyutlar içerisinde yer alan üst düzey düşünme $(\overline{\mathrm{X}}=3.98)$ ve akıl yürütme $(\overline{\mathrm{X}}=4.08)$ yüksek düzeyde; matematiksel düşünme becerisi $(\overline{\mathrm{X}}=3.54)$ ve problem çözme $(\overline{\mathrm{X}}=3.55)$ orta düzeyde yer almaktadır.

\subsection{Araştırmanın İkinci Alt Problemine İlişkin Bulgu ve Yorum}

Araştırmanın ikinci alt problemi olan "Sınıf öğretmeni adaylarının bireysel yenilikçilik durumları nasıldır?" sorusunu yanıtlamak amacıyla yapılan analizlere ilişkin bulgular Tablo 4 ve Tablo 5'de sunulmuştur.

Tablo 4. Sınıf öğretmeni adaylarının bireysel yenilikçilik durumları

\begin{tabular}{lcccccc}
\hline Değişken & $\mathbf{N}$ & $\mathbf{k}$ & $\mathbf{S s}$ & $\overline{\mathbf{X}}$ & $\overline{\mathbf{X}} / \mathbf{k}$ & Düzey \\
\hline Değişime direnç & 223 & 8 & .62 & 22.26 & 2.78 & Orta \\
Fikir önderliği & 223 & 5 & .62 & 18.44 & 3.68 & Yüksek \\
Deneyime açılklk & 223 & 5 & .66 & 19.36 & 3.87 & Yüksek \\
Risk alma & 223 & 2 & .86 & 6.83 & 3.41 & Orta \\
\hline Bireysel yenilikçilik & 223 & 20 & .39 & 66.91 & 3.34 & Orta \\
\hline
\end{tabular}

Tablo 4'e göre sınıf öğretmeni adaylarının bireysel yenilikçilik durumları incelendiğinde bireysel yenilikçilik puanının $\bar{X}=3.34$ olduğu; alt boyutlara ilişkin değişime direncin $\bar{X}=2.78$, fikir önderliğinin $\bar{X}=3.68$, deneyime açıklığın $\bar{X}=3.87$ ve risk almanın $\bar{X}=3.41$ puanlarına sahip olduğu ortaya çıkmıştır. Değişime direnç, 
risk alma ve bireysel yenilikçiliği orta düzeyde, fikir önderliği ve deneyime açıklık durumlarının yüksek düzeyde olduğu ortaya çıkmıştır.

Tablo 5. Sınıf öğretmeni adaylarının bireysel yenilikçilik durumları

\begin{tabular}{|c|c|c|}
\hline Bireysel yenilikçi durumu & $\mathbf{N}$ & $\%$ \\
\hline Gelenekçi & 7 & 3.1 \\
\hline Kuşkucu & 78 & 35.0 \\
\hline Sorgulayıcı & 124 & 55.6 \\
\hline Öncü & 11 & 4.9 \\
\hline Yenilikçi & 3 & 1.3 \\
\hline
\end{tabular}

Tablo 5'e göre sınıf öğretmeni adaylarının bireysel yenilikçilik durumlarına ilişkin analizler sonucunda 7'sinin (\%3.1) gelenekçi, 78'inin (\%35.0) kuşkucu, 124 'ünün (\%55.6) sorgulayıc1, 11'inin (\%4.9) öncü ve 3'ünün (\%1.3) yenilikçi olduğu sonucuna ulaşılmıştır.

\subsection{Araştırmanın Üçüncü Alt Problemine İlişkin Bulgu ve Yorum}

Araştırmanın üçüncü alt problemi olan "Sınıf öğretmeni adaylarının matematiksel düşünme becerileri ile bireysel yenilikçilik durumları arasında bir ilişki var mıdır?" sorusunu yanıtlamak amacıyla yapılan analizlere ilişkin bulgular Tablo 6'da sunulmuştur

Tablo 6. Sınıf öğretmeni adaylarının matematiksel düşünme ile bireysel yenilikçilikleri arasındaki korelasyon analizi

\begin{tabular}{|c|c|c|c|c|c|c|c|c|c|c|}
\hline Değişkenler & 1 & 2 & 3 & 4 & 5 & 6 & 7 & 8 & 9 & 10 \\
\hline $\begin{array}{l}\text { 1.Matematiksel } \\
\text { Düşünme Ölçeği }\end{array}$ & - & $.91 *$ & $.87 *$ & $.79 *$ & $.83^{*}$ & $.34 *$ & -.00 & $.21 *$ & $.49 *$ & $.23 *$ \\
\hline $\begin{array}{l}\text { 2.Üst Düzey Düşünme } \\
\text { Eğilimi }\end{array}$ & & - & $.76^{*}$ & $.66^{*}$ & $.68^{*}$ & $.36 *$ & .03 & $.24 *$ & $.47 *$ & $.23^{*}$ \\
\hline 3.Akıl Yürütme & & & - & $.87 *$ & $.67 *$ & $.34 *$ & .01 & $.23 *$ & $.48^{*}$ & $.19^{*}$ \\
\hline $\begin{array}{l}\text { 4.Matematiksel } \\
\text { Düşünme Becerisi }\end{array}$ & & & & - & $.50^{*}$ & $.14 *$ & -.10 & .08 & $.35^{*}$ & $.13^{* *}$ \\
\hline 5.Problem Çözme & & & & & - & $.30 *$ & .05 & $.15^{*}$ & $.39 *$ & $.24 *$ \\
\hline $\begin{array}{l}\text { 6.Bireysel Yenilikçilik } \\
\text { Ölçeği }\end{array}$ & & & & & & - & $.53^{*}$ & $.67 *$ & $.68^{*}$ & $.55^{*}$ \\
\hline 7.Değişime Direnç & & & & & & & - & -.10 & $-.13^{*}$ & .02 \\
\hline 8.Fikir Önderliği & & & & & & & & - & $.64 *$ & $.34 *$ \\
\hline 9.Deneyime Açıklık & & & & & & & & & - & $.45^{*}$ \\
\hline 10. Risk Alma & & & & & & & & & & - \\
\hline
\end{tabular}

$\mathrm{n}=223, * \mathrm{p}<.05, * * \mathrm{p}<.01$

Tablo 6’ya göre sınıf öğretmeni adaylarının matematiksel düşünme ölçeği ile bireysel yenilikçilik ölçeği puanları arasında anlamlı bir ilişkinin olduğu $(\mathrm{p}<.05)$ 
ortaya çıkmıştır. İlişkinin derecesi değerlendirildiğinde ise [r=.34] pozitif yönde düşük ilişki tespit edilmiştir. Bu noktada matematiksel düşünmenin bireysel yenilikçiliği etkilediği fakat bu etkinin düşük düzeyde olduğu söylenebilir. Ayrıca matematiksel düşünme durumları ile bireysel yenilikçilik ölçeği alt boyutları arasındaki ilişki incelendiğinde değişime direnç dışındaki alt boyutlarda pozitif yönde anlamlı ilişki $(\mathrm{p}<.05)$ bulunmuştur. Bireysel yenilikçilik ile matematiksel düşünme durumlarının alt boyutları arasındaki ilişki incelendiğinde ise tüm alt boyutlarda pozitif yönde anlamlı ilişki $(\mathrm{p}<.05)$ tespit edilmiştir. Buradan hareketle de matematiksel düşünme becerisinin geliştirilmesinin bireysel yenilikçiliklerinin de gelişmesini sağlayacağı söylenebilir.

\section{TARTIŞMA ve SONUÇ}

\subsection{Tartışma}

Sınıf öğretmeni adaylarının matematiksel düşünme düzeylerinin yüksek olduğu sonucuna ulaşılmıştır. Sınıf öğretmeni adaylarının yüksek düzeyde matematiksel düşünmeye sahip olmaları, ilkokul eğitimi sırasında yetiştirecekleri öğrencilerin düşünme süreçlerini geliştirecek olan etkinlikleri seçmelerini kolaylaştırılacaktır. Öğretmen adaylarının matematiksel düşünmesinin yüksek olması öğrencilerin matematiksel düşünme gelişimlerini takip etmek ve arttırabilmek için öğrenme ortamına ilgi çekici, düşünmeye yöneltici materyaller hazırlayarak gelmelerini; eğitim çıktılarının daha etkili ve verimli olmasını sağlayacaktır (Jacobs, Empson, Krause \& Pynes, 2015; Jacobs \& Empson, 2016). Bunun yanında öğrencinin matematiksel düşünme gelişiminin olumlu olarak desteklenmesi için öğretmenlerin ezberden uzak uygulama temelli öğretim ortamları hazırlanması gerekmektedir (Ersoy \& Başer, 2013). Bu öğrenme ortamlarının matematiksel düşünme düzeyi yüksek olan öğretmenler tarafından hazırlanması öğrencilerin bilgi ve kurallara dayalı düşünmesini engelleyerek sezgilere dayalı işlemler yapmalarını sağlayarak öğrencinin kaliteli bir gelişim geçirmesine olanak sağlayacaktır (Attridge \& Ingles, 2015; Bredefur, Carney, Hughes, \& Strother, 2015). Bu sonuçlar 1şı̆̆ında öğretmen adaylarının matematiksel düşüncelerinin geliştirilmesinin dolaylı olarak öğrencilerinin bilgi, beceri ve yaratıcılığını arttıracağı düşünülebilir.

Sınıf öğretmeni adaylarının bireysel yenilikçilik durumlarının orta düzeyde olduğu sonucuna ulaşılmıştır. Bireysel yenilikçiliğin orta düzeyde olması, öğretmen adaylarının yenilik arayışında oldukları, yeniliğe ulaşmaya daha yakın oldukları, olumlu güdülendikleri ve değişime karşı kaygılarının daha az olduğunun göstergesidir. Bu sonuç Akın Kösterelioğlu ve Demir'in (2014) çalışmalarının sonuçları ile benzerlik göstermekte olup öğretmenlik mesleğinin toplumlardaki değişimi gerçekleştirecek olan bir meslek grubu olduğunun göstergesidir. Ayrıca sınıf öğretmeni adaylarının bireysel yenilikçilik kategorileri incelendiğinde sorgulayıcı oldukları sonucuna ulaşılmıştır. Sorgulayıcı öğretmen adaylarının yenilikleri kabul etmeye karşı temkinli davrandıkları, risk alamadıkları söylenebilir. Benzer sonuçlara Kılıçer (2011), Çuhadar, Bülbül ve Ilgaz (2013), Çelik (2013), Korucu ve Olpak (2015), Örün, Orhan, Dönmez ve Kurt (2015), Gökçearslan, Karademir ve Korucu (2016) ve Deniz'in (2016) gerçekleştirdikleri araştırmalarda da rastlanmaktadır. Öğretmen adaylarının yenilikçi kategorisinde az bulunmasının yenilikçi fikirleri ve risk almayı hayat tarzı yapmadıklarının bir göstergesi olduğu söylenebilir. Öncü oldukları durumlarda öğretmen adayları öğrencilerine ve diğer bireylere bilgi aktarımında bulunarak yol gösterici bir görev edinmiş olurlar. Bu nedenlerden dolayı 
öğretmen adaylarının yenilikçi ve öncü kategorilerinde bulunmaları sayesinde öğrencilerin fikirlerini daha rahat ortaya koyacakları, yaratıcılıklarını arttırabilecekleri söylenebilir.

Sınıf öğretmeni adaylarının matematiksel düşünme durumları ile bireysel yenilikçilikleri arasında pozitif yönde anlamlı bir ilişki bulunmuştur. Bu bağlamda sınıf öğretmenlerinin matematiksel düşünme durumları yükseldiğinde bireysel yenilikçiliklerinin de artacağını söyleyebiliriz. Günümüzde bilgi çağının gereksinimlerini yerine getiren, gelişmeleri yakından takip eden, üst düzey becerilere sahip yenilikçi bireylerden oluşan bir toplum yaratmamız gerekir. Bireylerin üst düzey becerilerinin gelişmesi verilen eğitimle ilişkilidir. Eğitimin kalitesini arttırmak için en önemli faktör öğretmenin yetiştirilmesidir. Öğretmenlerin üst düzey bilişsel becerilere sahip olması gerekir. Bu beceriler içerisinde matematiksel düşünmenin öğretmenlerde geliştirilmesi dolaylı olarak öğrencilerin düşünme kapasitelerini geliştirecek, yenilikçi öğrenciler yaratacaktır (Stein, Grover \& Henningsen, 1996). Ayrıca öğretmenlerde matematiksel düşüncenin gelişimi sağlandığında öğrenme ortamında uygulanan metotların çeşitliliği artacak bu durumda öğrencinin gelişimi ile birlikte bilimsel gelişmeyi de sağlayacaktır (Greeno \& Goldman, 1998). Bilimsel gelişmeyi sağlayacak olanlar ise yenilikçiliği benimsemiş olan bireylerdir. Matematiksel düşünme ile bireysel yenilikçilik arasında dolaylı ya da doğrudan ilişkinin olduğunu Dennis ve Hamm (2010), Jacobson ve Kozma (2011), Van de Walle, Karp ve BayWilliams (2014), Dursun (2015) yaptıkları çalışmalarda belirtmişlerdir. Bu çalışmalar araştırmamızın sonuçlarından biri olan matematiksel düşünme ile bireysel yenilikçilik arasındaki ilişkiyi desteklemektedir. Ayrıca matematiksel düşünmenin alt boyutları ile bireysel yenilikçiliğin alt boyutları arasında da pozitif yönde anlamlı bir ilişki bulunmuştur. $\mathrm{Bu}$ durumda matematiksel düşünme ile bireysel yenilikçilik ilişkisinin göstergesi olması bakımından önemli olduğu söylenebilir.

\subsection{Sonuç}

Araştırma sonuçlarına göre, sınıf öğretmeni adaylarının matematiksel düşünme durumlarının yüksek, bireysel yenilikçiliklerine ilişkin durumlarının orta düzeyde, bireysel yenilikçilik kategorilerinden en fazla sorgulayıcı olduğu ortaya çıkmıştır. Matematiksel düşünme ile bireysel yenilikçilik durumları arasındaki ilişki incelendiğinde düşük düzeyde pozitif yönde anlamlı bir ilişkinin olduğu ortaya çıkmıştır. Matematiksel düşünmenin alt boyutları ile bireysel yenilikçiliği alt boyutları arasında pozitif bir ilişkinin olduğu ortaya çıkmıştır.

\section{3. Öneriler}

Öğretmen adaylarında matematiksel düşünmeyi geliştirecek çalışmaların yapılması gerekmektedir. Yenilikçi düşünen bireyler yetiştirecek olan öğretmen adaylarına bilgiye ulaşma, bunu etkili bir şekilde kullanmanın nasıl olması gerektiği konusunda bilgi paylaşımları lisans eğitimleri sırasında yapılmalıdır. Ayrıca matematiksel düşünmeyi geliştirici etkinliklerin tasarlanması öğrencinin gelecek yaşantısında bireysel yenilikçiliğini arttıracağından bu etkinliklere önem verilmelidir. Sınıf öğretmenlerinin yetiştirilmesi aşamasında matematiksel düşünmeyi geliştirici etkinliklerin planlanması ve bunların öğretmen adaylarına nasıl, ne şekilde geliştireceklerine dair eğitimin verilmesi gerekmektedir. Araştırmacılar noktasında ise bu çalışmaların matematiksel düşünme çalışmaları ile destelenerek uygulamalı çalışmalar yapılmalıdır. 


\section{KAYNAKLAR}

Akın-Kösterelioğlu, M. \& Demir, F. (2014). Öğretmenlerin bireysel yenilikçilik düzeyinin öğretmen liderliğine etkisi. International Periodical for the Languages, Literature and History of Turkish or Turkic (Turkish Studies), 26, 247-256.

Attridge, N. \& Inglis, M. (2015). Increasing cognitive inhibition with a difficult prior task: implications for mathematical thinking. ZDM Mathematics Education, 47(5), 723-734.

Braak, J. (2001). Individual characteristics influencing teachers' classuse of computers. Journalof Educational Computing Research, 25(2), 141-157.

Bredefur, J. L.,Carney, M., Hughes, G. \& Strother S. (2015). Framing professional development that promotes mathematical thinking. STEM Education: An Overview of Contemporary Research, Trends and Perspectives, 1, 217236.

Breen, S. \& O'Shea, A. (2010). Mathematical thinking and task design, Irish Math. Soc. Bulletin, 66, 39-49. (http://www.maths.tcd.ie/pub/ims/bull66 /ME6601.pdf adresinden 12.02.2016 tarihinde erişilmiştir.)

Çelik, K. (2013). The relationship between individual innovativeness and selfefficacy levels of student teachers. International Journal of Scientific Research in Education, 6(1), 56-67.

Çelikten, M., Şanal, M. \& Yeni, Y. (2005). Öğretmenlik mesleği ve özellikleri. Sosyal Bilimler Enstitüsü Dergisi, 19(2), 207-237.

Çuhadar, C., Bülbül, T. \& Ilgaz, G. (2013). Öğretmen adaylarının bireysel yenilikçilik özellikleri ile teknopedagojik eğitim yeterlikleri arasındaki ilişkinin incelenmesi. Illkögretim Online, 12(3), 797-807.

Deniz, S. (2016). Öğretmen adaylarının bireysel yenilikçilik özellikleri. International Periodical for the Languages, Literature and History of Turkish or Turkic (Turkish Studies), 11(9), 267-278.

Dennis, A. \& Hamm, M. (2010). Creativity, innovation, and differentiation. Problem solving and inquiry in math, science, and technology. Demystify Math, Science, and Technology. Creativity, innovation, and problem solving. R owman \& Littlefield Publishers, Inc., United Kingdom.

Dursun, Ş. (2015). Matematik öğretimi ve inovasyon. Batman Üniversitesi Yaşam Bilimleri Dergisi, 5(2), 163-175.

Ersoy, E. \& Başer, N. (2013). Matematiksel düşünme ölçeğinin geliştirilmesi. Kastamonu Eğitim Fakültesi Dergisi, 21(4), 1471-1486.

Fullan, M. \& Pomfret, A. (1977). Research on curriculum and instruction implementation. Review of Educational Research, 47(1), 335-397.

Greeno, J.G. \& Goldman, S.V. (1998). Thinking practices in mathematics and science learning. New York and London: Routledge (Taylor \& Francis Group) Publishers.

Gökçearslan, Ş., Karademir, T. \& Korucu, A.T. (2017). Preservice teachers' level of web pedagogical content knowledge assessment by individual 
innovativeness. Journal of Educational Computing Research, 55(1), 70-94. DOI: $10.1177 / 0735633116642593$.

Henderson, P. (2002). Materials development in support of mathematical thinking, <http://blue.butler.edu/phenders/iticse2002WG.rtf> Son erişim $15 / 04 / 2016$.

Herron, L. (1992). Cultivating corporation entrepreneurs. Human Resource Planning, 15(4), 3-14.

Jacobs, V.R. \& Empson, S.B. (2016). Responding to children's mathematical thinking in the moment: an emerging framework of teaching moves. ZDM Mathematics Education, 48(1), 185-197.

Jacobs, V. R., Empson, S. B., Krause, G. H., \& Pynes, D. (2015). Responsive teaching with fractions. Paper presented at the 2015 annual meeting of the Research Conference of the National Council of Teachers of Mathematics, Boston.

Jacobson, M.J. \& Kozma, R.B. (2011). Innovations in Science and Mathematics education. Taylor \& Francis e-Library.

Karasar, N. (2014). Bilimsel araştırma yöntemi. Ankara: Nobel Yayın Dağıtım.

Kılıçer, K. (2011). Bilgisayar ve ögretim teknolojileri ĕgitimi öğretmen adaylarının bireysel yenilikçilik profilleri. Yayımlanmamış doktora tezi, Anadolu Üniversitesi, Eğitim Bilimleri Enstitüsü, Eskişehir.

Kılıçer, K. \& Odabaşı, H.F. (2010) Bireysel Yenilikçilik Ölçeği (BYÖ): Türkçe'ye uyarlama, geçerlik ve güvenirlik çalışması. Hacettepe Üniversitesi Ĕ̆itim Fakültesi Dergisi, 38, 150-164.

Korucu, A.T. \& Olpak, Y.Z. (2015). Öğretmen adaylarının bireysel yenilikçilik özelliklerinin farklı değişkenler açısından incelenmesi. Eğitim Teknolojisi Kuram ve Uygulama, 5(1), 111-127.

Mason, J., Burton, L. \& Stacey, K. (2010). Thinking mathematically (Second Edition). Harlow England: Pearson Education Limited.

Milli Eğitim Bakanlığı (MEB), (2015). Milli Eğitim Bakanlığı Talim ve Terbiye Kurulu Başkanlığ1, http://ttkb.meb.gov.tr/www/ogretimprogramlari/icerik/72 adresinden 08.03.2016 tarihinde edinilmiştir.

Mubark, M. (2005). Mathematical thinking and mathematical achievement of students in the year of 11 scientific stream in Jordan. Doctoral dissertation, New Castle University.

National Council of Teachers of Mathematics (2000). Principles and standarts for school mathematics, Reston, VA: NCTM.

Örün. Ö., Orhan, D., Dönmez, P. \& Kurt, A.A. (2015). Öğretmen adaylarının bireysel yenilikçilik profilleri ve teknoloji tutum düzeyleri arasındaki ilişkinin incelenmesi. Trakya Üniversitesi Ĕgitim Fakültesi Dergisi, 5(1), 65-76.

Polya, G. (1945). How to solve it. A New aspect of mathematical method. Princeton University Press. Princeton, New Jersey.

Rogers, E. M. (2003). Diffusion of innovations. New York, A Division of Simon \& Schuster, İnc. 
Stein, M. K., Grover, B.W. \& Henningsen, M. (1996). Building student capacity for mathematical thinking and reasoning: An analysis of mathematical tasks used in reform classrooms. American Educational Research Journal, 33(2), 455-488.

Şişman, M. (2007). Eğitim bilimine giriş. Ankara: Pegem Yayınevi.

Tataroğlu-Taşdan, B., Erduran, A. \& Çelik, A. (2013). Matematik öğretmen adaylarının matematiksel düşünme ve öğrencilerin matematiksel düşünmelerinin geliştirilmesi hakkındaki görüşlerinin incelenmesi. Kastamonu Eğitim Dergisi, 21(4), 1487-1504.

Van De Walle, J. A., Karp, K. S. \& Bay-Williams, J. M. (2014). Ilkokul ve ortaokul matematiği gelişimsel yaklaşımla öğretim. (Çeviri Editörü: Soner Durmuş). Ankara: Nobel Akademik Yayıncılık.

Wilson, P. H., Mojica, G.F. \& Confrey, J. (2013). Learning trajectories in teacher education: Supporting teachers' understandings of students' mathematical thinking. The Journal of Mathematical Behavior, 32, 130-121.

$\mathrm{Xu}, \mathrm{Z}$. \& Chen, H. (2010). Research and practice on basic composition and cultivation pattern of college students' innovative ability. International Education Studies, 3, 51-55.

Yeşildere, S. \& Türnüklü, E.B. (2007). Öğrencilerin matematiksel düşünme ve akıl yürütme süreçlerinin incelenmesi. Ankara Üniversitesi Ĕ̆itim Bilimleri Fakültesi Dergisi, 40(1), 181-213.

Yıldırım, C. (2000). Matematiksel düşünme (3. baskl). İstanbul: Remzi Kitabevi.

Yuan, F. \& Woodman, R.W. (2010). Innovative behavior in the workplace: The role of performance and image outcome expectations. Academic Management Journal, 53(2), 323-342. 


\section{EXTENDED ABSTRACT}

\section{Introduction}

It is important to identify the relationship between mathematical thinking and individual innovations of pre-service classroom teachers. Since, when they begin to work as primary school teacher, mathematical thinking and individual innovations enable than to choose the activities which develop mathematical thinking. In addition to that, because raising the individuals having individual innovation increases the society's development and provides emerging the new ideas. For this reason it is important to identify the relationship between mathematical thinking and individual innovation

Purpose of study: The aim of the study is determine the relationship between mathematical thinking and individual innovations of pre-service classroom teachers. In accordance with this goal, the subgoals of the study are below:

What is the mathematical thinking level of the pre-service classroom teachers?

What is the individual innovation level of the pre-service classroom teachers?

Is there a relationship between mathematical thinking and individual innovation of the preservice classroom teachers?

\section{Method}

The correlational research method was used. The 385 studentswhostudied in Mugla Sitk1 KocmanUniversity, Faculty of education and Department of Primary School Teacher in 2015-2016 academic year constituted the population of this study. The sapling was constituted from 223 pre-service classroom teachers in this department. Mathematical Thinking Scale and Individual Innovation Scale were used as data collection instrument. The data collection tools applied before analyzing the data in the study were scored and entered into the SPSS 21.0 program. Confirmatory Factor Analysis was used to determine the construction validity of the used scales, and Cronbach Alpha analyzes were performed when reliability was determined. Frequency $(\mathrm{n})$ and percentage $(\%)$ mean $(\overline{\mathrm{X}})$ and standard deviation $(\mathrm{Ss})$ values were calculated in the description of mathematical thinking and individual innovativeness of classroom teachers. Pearson Product Moments Correlation Analysis was used to determine the relationship between mathematical thinking and individual innovation.

\section{Finding and Results}

It was found that the mathematical thinking level of the participants was high from the subcategories the level of higher order thinking and raising skill were high and mathematical thinking and problem solving skills were moderate level. Primary school teacher candidates should have a high level of mathematical thinking and facilitate the selection of activities that will improve the thinking process of students in primary school education. As a result, it can be considered that the development of mathematical thinking of teacher candidates will affect the knowledge, skill and creativity of the student.

The results also showed that the level of individual innovation was moderate, from the subcategories, the relationship of idea and open to experience were high taking risk and resistance to change were moderate. The moderate level of individual innovation is that prospective teachers are in search of innovation, are closer to reaching newness, positive motivated and less concerned about change. In the categories of individual innovation 7 of the teachers were found as traditionalist (3.1\%), 78 of them were sceptic (35\%), 124 of them were critical (55.6\%), 11 of them were leader (4.9\%), and 3 of them were innovative (1.3\%).

It was found that a significant positive relationship [r=34] between mathematical thinking and individual innovation of pre-service classroom teacher. In this context, we can say that when the mathematical thinking situation of the class teachers increases, the levels of individual innovativeness will increase. In addition, there was a significant positive correlation 
between the sub-dimensions of mathematical thinking and sub-dimensions of individual innovation. This can be said to be important in that it is indicative of the relationship between mathematical thinking and individual innovation.

\section{Discussion, Conclusions and Recommendations}

According to the result of this present study, it was found that the mathematical thinking level of the participants was high; the level of individual innovation was moderate. The high level of mathematical thinking of prospective teachers will enable students to be more effective and productive in their output by engaging in interesting and thought-provoking materials in the learning environment in order to follow andimprovemathematicalthinkingdevelopment (Jacobs, Empson, Krause and Pynes, 2015; Jacobs and Empson, 2016).

From the categories of the individual innovation, critical had the highest score in this study. It can be said that interrogating teacher candidates are cautious about accepting innovations and do not take risks. Similar results have beenfound in theresearches of Kiliçer (2011), Çuhadar, Bülbül and Ilgaz (2013), Çelik (2013), Korucu and Olpak (2015), Örün, Orhan, Dönmez and Kurt (2015), Gökçearslan, Karademir and Korucu (2016), Deniz (2016).

As for the relationship between mathematical thinking and individual innovation, a moderate positive relationship was observed. Dennis andHamm (2010), JacobsonandKozma (2011),Van de Walle, Karpand Bay-Williams (2014), Dursun (2015) foundthatthere is a direct or indirect relationship between mathematical thinking and individual innovativeness.

Since, designing the activities developing mathematical thinking improves student' individual innovation in their future life this activities should be given importance. When the process of educating the pre-service classroom teachers the activities developing mathematical thinking should be planned. Besides pre-service classroom teachers should be informed in terms of how to develop these activities. 